\title{
O Modelo Padrão da Física de Partículas
}

(The Standard Model of Particle Physics)

\author{
Marco Antonio Moreira ${ }^{1}$ \\ Instituto de Física, Universidade Federal do Rio Grande do Sul, Porto Alegre, RS, Brasil \\ Recebido em 28/11/2007; Revisado em 17/7/2008; Aceito em 26/2/2009; Publicado em 30/4/2009
}

\begin{abstract}
Inicialmente, apresenta-se, de modo simplificado, o Modelo Padrão como uma teoria sofisticada que identifica as partículas elementares e suas interações. Depois, no âmbito dessa teoria, focalizam-se aspectos - o vácuo não é vazio; partículas nuas e vestidas; matéria escura e vento escuro; matéria e antimatéria; o campo e o bóson de Higgs; neutrinos oscilantes - que podem ser motivadores do ponto de vista do ensino e da aprendizagem da física. Finalmente, discute-se a provável superação dessa teoria por outra mais completa.
\end{abstract}

Palavras-chave: Modelo Padrão, partículas elementares, ensino de física.

Initially, the Standard Model is presented, in a simplified way, as a sophisticated theory that identifies the elementary particles and describes how they interact. Then, within the scope of this theory, some aspects the vacuum is not empty; naked and dressed particles; dark matter and dark wind; matter and antimatter; the Higgs field and the Higgs boson; oscillating neutrinos - are approached as motivating topics for the teaching and learning of physics. Finally, the eventual superseding of this theory by a more complete one is discussed.

Keywords: Standard Model, elementary particles, physics teaching.

\section{O Modelo Padrão da Física de Partí- culas}

O chamado Modelo Padrão das partículas elementares não é propriamente um modelo, é uma teoria. E das melhores que temos. Aliás, na opinião de muitos físicos, a melhor de todas sobre a natureza da matéria. Por exemplo, segundo Gordon Kane [1], um físico teórico da Universidade de Michigan:

...o Modelo Padrão é, na história, a mais sofisticada teoria matemática sobre a natureza. Apesar da palavra "modelo" em seu nome, o Modelo Padrão é uma teoria compreensiva que identifica as partículas básicas e especifica como interagem. Tudo o que acontece em nosso mundo (exceto os efeitos da gravidade) resulta das partículas do Modelo Padrão interagindo de acordo com suas regras e equações. (p. 58)

De acordo com o Modelo Padrão, léptons e quarks são partículas verdadeiramente elementares, no sentido de não possuírem estrutura interna. Partículas que têm estrutura interna são chamadas de hádrons; são constituídas de quarks: bárions quando formadas por três quarks ou três antiquarks, ou mésons quando constituídas por um quark e um antiquark. ${ }^{2}$

Há seis léptons (elétron, múon, tau, neutrino do elétron, neutrino do múon e neutrino do tau) e seis quarks [quark up $(\boldsymbol{u})$ quark down $(\boldsymbol{d})$, quark charme $(\boldsymbol{c})$, quark estranho $(\boldsymbol{s})$, quark bottom (b) e quark top $(\boldsymbol{t})$ ]. Porém, os quarks têm uma propriedade chamada cor ${ }^{3}$ e podem, cada um, apresentar três cores (vermelho, verde e azul). Há, portanto, 18 quarks. Contudo, como a cada partícula corresponde uma antipartícula, ${ }^{4}$ existiriam no total 12 léptons e 36 quarks.

O elétron é o lépton mais conhecido e o próton e o nêutron os hádrons mais familiares. A estrutura interna do próton é $\boldsymbol{u} \boldsymbol{u} \boldsymbol{d}$, ou seja, dois quarks $\boldsymbol{u}$ e um $\boldsymbol{d}$; a do nêutron é $\boldsymbol{u} \boldsymbol{d} \boldsymbol{d}$, isto é, dois quarks $\boldsymbol{d}$ e um $\boldsymbol{u}$. O méson $\pi^{+}$é formado por um antiquark $\boldsymbol{d}$ e um quark $\boldsymbol{u}$, o méson $\pi^{-}$é constituído por um antiquark $\boldsymbol{u}$ e um quark $\boldsymbol{d}$. E assim por diante, ou seja, a grande maioria das chamadas partículas elementares são hádrons e estes são formados por três quarks ou três antiquarks

\footnotetext{
${ }^{1}$ E-mail: moreira@if.ufrgs.br, www.if.ufrgs.br/ $\sim_{\text {moreira }}$

${ }^{2}$ Antiquark é a antipartícula do quark.

${ }^{3}$ Trata-se de uma propriedade, não uma cor propriamente dita. Vermelho, verde e azul são apenas aspectos dessa propriedade. Assim como a carga elétrica, que é também uma propriedade de certas partículas, pode ser positiva ou negativa, a propriedade cor, que poderia ser chamada de carga cor, apresenta três variedades que foram chamadas de vermelho, verde e azul.

${ }^{4}$ De um modo geral, uma antipartícula tem a mesma massa e o mesmo spin da partícula em questão, porém cargas opostas. 
(bárions) ou por um quark e um antiquark (mésons).

Em princípio, a teoria dos quarks, a Cromodinâmica Quântica, não proibe a existência de partículas com estrutura mais complexa do que três quarks, três antiquarks ou um par quark-antiquark. Todavia, apenas recentemente [2] físicos experimentais têm apresentado evidências de partículas com cinco quarks, ou seja, pentaquarks, como o teta mais, formado por quatro quarks e um antiquark. Mas isso ainda depende de resultados experimentais adicionais.

Uma característica peculiar dos quarks é que eles têm carga elétrica fracionária, $(+2 / 3 e)$ para alguns tipos e $(-1 / 3 e)$ para outros. No entanto, quarks nunca foram detectados livres, estão sempre confinados em hádrons, de tal modo que a soma algébrica das cargas dos quarks que constituem um determinado hádron é sempre um múltiplo inteiro de $e$. O próton, por exemplo, é formado por dois quarks de carga $(+2 / 3 e)$ e um quark de carga $(-1 / 3 e)$ de modo que sua carga é $(2 / 3$, $+2 / 3,-1 / 3) e$, ou, simplesmente, e. Quer dizer, o quantum da carga elétrica continua sendo $e\left(1,6 \times 10^{-19} \mathrm{C}\right)$.

Resumindo, segundo o Modelo Padrão a grande quantidade de partículas elementares até hoje detectadas, cerca de 300, em aceleradores/colisores de partículas ou em raios cósmicos, pode ser agrupada em léptons, quarks e hádrons ou em léptons e hádrons, visto que os quarks são constituintes dos hádrons ou, ainda, em léptons, bárions e mésons, pois os hádrons podem ser divididos em bárions e mésons.

Mas como foi dito no início, o Modelo Padrão é uma teoria compreensiva que identifica as partículas básicas e especifica como elas interagem. Vamos então às interações.

Há na natureza quatro tipos de interações fundamentais: gravitacional, eletromagnética, forte $\epsilon^{5} \mathrm{e}$ fraca. Cada uma delas é devida a uma propriedade fundamental da matéria: massa (interação gravitacional), carga elétrica (interação eletromagnética), cor (interação forte) e carga fraca (interação fraca). Se chamarmos cada uma dessas propriedades de carga teremos quatro cargas: carga massa, carga elétrica, carga cor e carga fraca.

Assim sendo, há também quatro forças fundamentais na natureza: força gravitacional, força eletromagnética, força cor ${ }^{6}$ e força fraca. Todas aquelas forças que parecem ser distintas - como forças elásticas, forças de atrito, forças intermoleculares, interatômicas, interiônicas, forças de viscosidade, etc. - são casos particulares ou resultantes dessas quatro forças fundamentais.

Mas como se dá a interação? Quem "transmite a mensagem" da força entre as partículas interagentes? Isso nos leva às partículas mediadoras ou partículas de força ou, ainda, partículas virtuais.

As interações fundamentais ocorrem como se as partículas interagentes "trocassem" outras partículas entre si. Essas partículas mediadoras seriam os fótons na interação eletromagnética, os glúons na interação forte, as partículas $W$ e $Z$ na interação fraca e os grávitons (ainda não detectados) na interação gravitacional. Quer dizer, partículas eletricamente carregadas interagiriam trocando fótons, partículas com carga cor interagiriam trocando glúons, partículas com carga fraca trocariam partículas $\mathrm{W}$ e $\mathrm{Z}$ enquanto partículas com massa trocariam grávitons.

As partículas mediadoras podem não ter massa, mas têm energia, ${ }^{7}$ ou seja, são pulsos de energia. Por isso, são chamadas de virtuais. Dos quatro tipos de partículas mediadoras, $\frac{8}{8}$ as do tipo W e Z têm massa, mas é comum chamá-las todas de partículas virtuais.

Poder-se-ia, então, dizer que as partículas de matéria ou partículas reais ${ }^{9}$ (léptons, quarks e hádrons) interagem trocando partículas virtuais (fótons, glúons,

\footnotetext{
${ }^{5} \mathrm{~A}$ interação forte pode ser dividida em fundamental e residual; a fundamental é a própria interação forte, a residual decorre de balanços imperfeitos das atrações e repulsões entre os quarks que constituem os hádrons.

${ }^{6}$ Assim como a interação forte pode ser distinguida entre fundamental e residual, a força cor pode ser diferenciada em força cor forte e força cor residual. Ou seja, a cada interação corresponde uma força, então, se a interação forte pode ser interpretada como fundamental ou residual, correspondentemente, pode-se falar em força cor forte e força cor residual. A força cor residual pode ser entendida através de uma analogia com a força eletromagnética, a chamada força de Van der Waal's, entre dois átomos neutros ou com a força intermolecular entre duas moléculas neutras. Assim como essas forças resultam de um balanço imperfeito das atrações e repulsões entre as cargas elétricas existentes nesses átomos e moléculas, a força forte entre duas partículas sem cor (i.e., neutras em relação à propriedade chamada cor) é uma força (residual) decorrente de um balanço imperfeito das atrações e repulsões entre os quarks que constituem essas partículas. [3, p.G-9]. Portanto a força forte entre hádrons (partículas sem cor) que está sendo aqui chamada de força cor residual é apenas uma manifestação de uma força mais forte e mais fundamental - a força cor - que atua entre quarks existentes dentro de cada hádron.

${ }^{7}$ Lembremos que há uma equivalência entre massa e energia, respectivamente.

${ }^{8}$ Mésons também podem atuar como partículas mediadoras, mas no caso da interação forte residual. São os quanta do campo mesônico, o qual não é um campo fundamental como o eletromagnético, o forte, o fraco e o gravitacional.

${ }^{9}$ As partículas que estão aqui sendo consideradas reais porque têm massa podem também ser virtuais como, por exemplo, os pares elétron-pósitron virtuais mencionados na seção o vácuo não é vazio, tudo depende da energia. Partículas reais podem ir de um ponto A a um ponto B, conservam energia e fazem clicks em contadores Geiger. Particulas virtuais não fazem nada disso. As particulas mensageiras, ou partículas de força, podem ser reais, mas mais frequentemente aparecem na teoria como virtuais, de modo que muitas vezes são sinônimos, ou seja, considera-se que as partículas mediadoras são virtuais. [4, p. 278]. Partícula virtual é um construto lógico: partículas podem ser criadas tomando energia "emprestada" de alguma fonte e a duração do empréstimo é governada pela relação de incerteza de Heisenberg $\Delta E \Delta T>h / 2 \pi$, o que significa que quanto maior a energia "emprestada" menor o tempo que uma partícula virtual pode existir (ibid). Por exemplo, se houver disponibilidade de energia, um elétron pode emitir um fóton real que fará click em um detector Geiger real (ibid). Em resumo, tanto as partículas usuais (elétrons, múons, quarks,...) como as partículas mediadoras podem reais ou virtuais, podem estar em um estado real ou virtual.
} 
W e Z, e grávitons). Aqui é preciso levar em conta que as partículas de matéria podem ter mais de uma carga, de modo que experimentariam várias interações e forças, mas o âmbito da interação pode variar muito, a tal modo que em um determinado domínio uma certa interação seja irrelevante. A força gravitacional, por exemplo, é negligenciável no domínio subatômico. Quer dizer, embora existam quatro interações fundamentais, quatro cargas e quatro forças isso não quer dizer que todas as partículas tenham as quatro cargas e experimentem as quatro interações.

Mas faltam os campos! Os quatro campos. Sabemos que, na gravitação de Newton, um corpo com massa cria em torno de si um campo gravitacional, um campo de força que exerce uma força sobre outro corpo massivo e vice-versa. Analogamente, um corpo carregado eletricamente, cria um campo eletromagnético (se estiver em repouso, percebe-se apenas seu componente elétrico, se estiver em movimento manifesta-se também o componente magnético) e exerce uma força eletromagnética sobre outro corpo eletrizado e vice-versa.

Da mesma forma, há o campo da força forte e o campo da força fraca. Ou seja, há quatro campos fundamentais: o eletromagnético, o forte, o fraco e o gravitacional.10 As partículas mediadoras são os quanta dos campos correspondentes: os fótons são os quanta do campo eletromagnético, os glúons são os quanta do campo forte, as partículas $\mathrm{W}$ e $\mathrm{Z}$ do campo fraco e os grávitons seriam os quanta do campo eletromagnético.

Em outras palavras, os quatro campos fundamentais são o campo de fótons (eletromagnético), o de glúons (forte), o de partículas $\mathrm{W}$ e Z (fraco) e o de grávitons (gravitacional).

O problema nessa bela simetria de quatro cargas, quatro interações, quatro forças, quatro tipos de partículas mediadoras e quatro campos é que nenhum gráviton foi ainda detectado e a gravidade, em si, não encaixa bem nessa teoria que se convencionou chamar de Modelo Padrão. Este assunto será retomado mais adiante.

Para finalizar esta seção, apresenta-se, na Fig. 1, uma visão esquemática do Modelo Padrão. Como consta na legenda dessa figura, trata-se de uma simplificação.

Feito isso, o restante deste trabalho será dedicado a abordar aspectos dessa teoria que poderão ser motivadores do ponto de vista do ensino e da aprendizagem da física.

\section{O vácuo não é vazio}

Na seção anterior falamos de partículas virtuais, como os fótons e os gluóns, ou seja, partículas sem massa.
Pois bem, quando a incerteza ${ }^{11}$ na energia é mais que o dobro da massa do elétron (tal como ocorre a uma distância de aproximadamente $10^{-11} \mathrm{~cm}$ ) algo muito estranho pode ocorrer no vácuo: a produção de um par de partículas consistindo de um elétron e um pósitron. Se, de alguma forma, houver um suprimento de energia de fora do vácuo esse par tornar-se-á um par de partículas reais, sem violar a conservação da energia. Se não acontecer isso, o par desaparecerá tão rápido quanto foi produzido. Ou seja, o par elétron - pósitron é virtual, mas isso significa então que o vácuo está cheio de um grande número (essencialmente infinito) de pares elétron-pósitron virtuais. [5, p. 146].

Então, além de fótons e glúons há também elétrons e pósitrons virtuais, e outras partículas como múons e antimúons virtuais. De um modo geral, uma partícula virtual é uma "partícula que não aconteceu": não tem massa e existe apenas durante um curto período de tempo em uma pequena região do espaço. As relações de incerteza são responsáveis pelo aparecimento de partículas virtuais na física (ibid.). Elas têm importância em distâncias muito pequenas, mas são irrelevantes na física macroscópica.

Por exemplo, podemos supor que o vácuo está cheio de pares virtuais de múons e antimúons que normalmente não são detectados. Porém, em um experimento de aniquilação de um elétron e um pósitron (reais) em um acelerador/colisor de partículas aparecem múons reais que são observados nos detectores de partículas. De onde vieram? Um par múon-antimúon virtual recebeu a energia resultante da aniquilação e deixou a região (muito pequena) onde ocorreu a interação, como um par de múons reais.

O interessante de tudo isso é que o vácuo então não é vazio. O que parece tão simples macroscopicamente é um sistema muito complicado na teoria quântica.

Na verdade, identificar vácuo com espaço não ocupado por alguma coisa é uma concepção errônea inclusive no domínio da física clássica, pois, mesmo quando não há matéria em uma região do espaço ela continua preenchida e percorrida por campos e ondas. Não é desprovido de qualidades o espaço onde estão e se movem objetos ou sistemas e, ainda que possamos dizer que um objeto se desloca no vácuo quando não encontra outras partículas em seu trajeto, o espaço clássico nunca é literalmente vazio [6, p. 89].

Mas não se trata do velho conhecido éter que físicos de outras épocas propuseram como preenchendo todo o espaço e servindo de meio de propagação da luz e de outras ondas eletromagnéticas. Isso deverá ficar claro nas próximas seções.

\footnotetext{
${ }^{10} \mathrm{O}$ que se está buscando é manter a simetria, dizendo que há em quatro campos fundamentais, quatro cargas, quatro interações e quatro tipos de partículas mediadoras; na verdade, é só na gravitação newtoniana que um corpo com massa cria em torno de si um campo gravitacional, não na relatividade geral.

${ }^{11}$ De acordo com as relações de incerteza de Heisenberg quanto mais precisas as medidas do momentum ou da energia de uma partícula maiores as incertezas em medições no espaço e no tempo.
} 


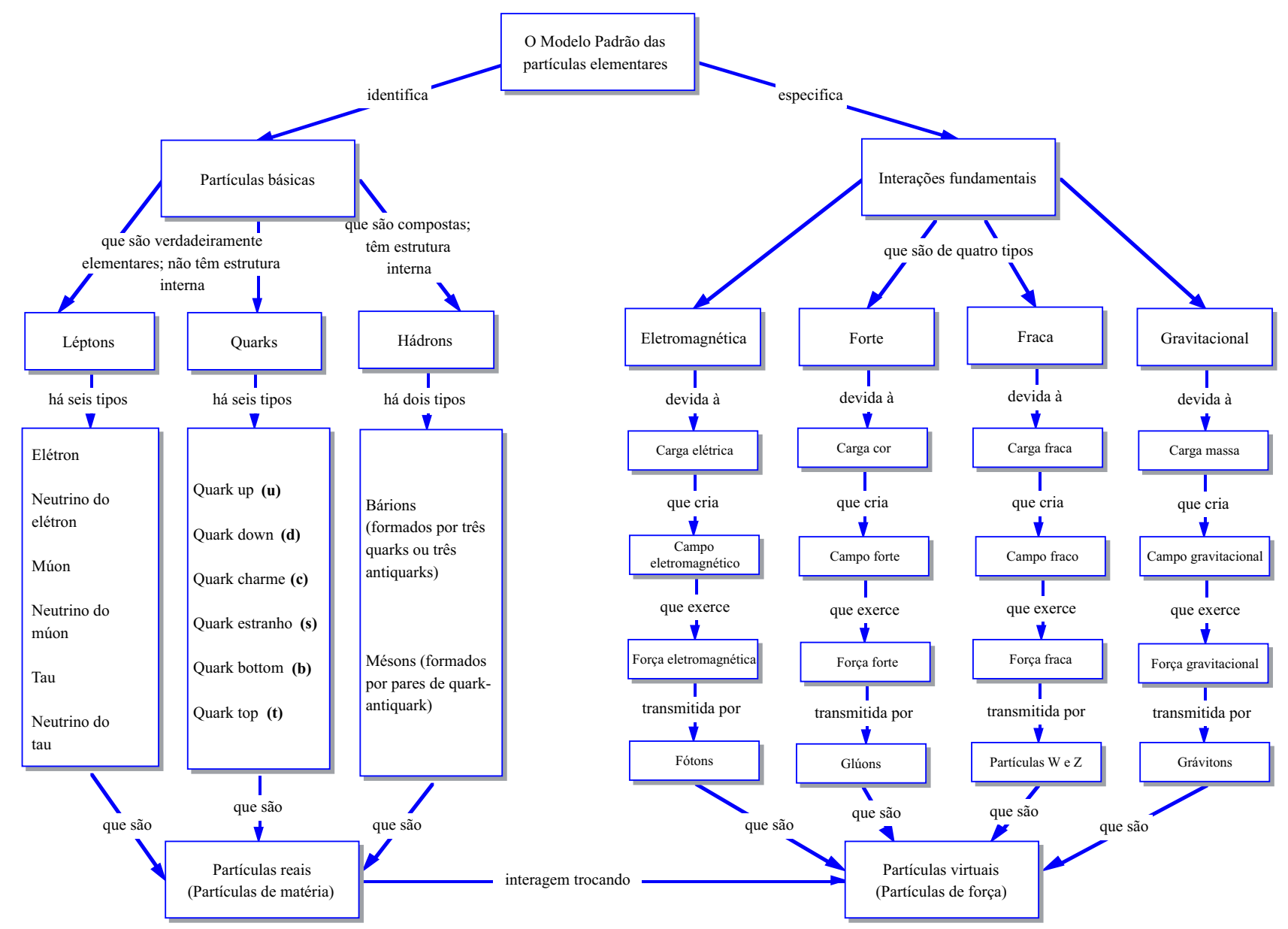

Figura 1 - Um esquema simplificado para o Modelo Padrão. Nesse esquema não é feita nenhuma alusão ao fato de que para cada partícula existe uma antipartícula, não se considera que os quarks têm a propriedade cor que se apresenta em três variedades (de modo que seria 18 o número de quarks) e que a interação forte pode se apresentar como fundamental ou residual (que seria mediada por mésons). Além disso, sugere que a interação gravitacional está perfeitamente integrada ao Modelo Padrão, o que ainda não ocorreu e talvez nem venha a ocorrer. Sugere também que as partículas $\mathrm{W}$ e Z são, de fato, virtuais, mas elas podem ser também reais como foi explicado na nota 8. É uma visão simplificada buscando destacar a simetria da teoria. Por isso, é preciso aceitá-la criticamente.

\section{Partículas nuas e vestidas}

Suponhamos que um elétron fosse colocado no vácuo. Poder-se-ia pensar que nada aconteceria, porém como o vácuo está cheio de pares elétron-pósitron virtuais, o elétron sendo negativo repeliria todos os elétrons virtuais e atrairia todos os pósitrons virtuais dos pares existentes na região do vácuo em torno de si. O elétron ficaria, assim, envolto por uma nuvem de pósitrons virtuais. O vácuo ficaria então polarizado pelo elétron [5, p. 148].

Qual o efeito disso? A carga do elétron fica parcialmente blindada pela nuvem do pósitrons virtuais. De longe não faz diferença. O que se "vê" é o elétron e a nuvem como um todo e não se pode distinguir que parte da carga do elétron é dele mesmo e que parte é da nuvem polarizadora. É o elétron físico, conhecido, que gera corrente nos fios e que tem carga - $e$. É o elétron do "dia-a-dia": o elétron "vestido", ou seja, com a nuvem.

Um elétron sem a nuvem de pósitrons virtuais é chamado de "elétron nu". Em altas energias, o efeito da polarização pode ser percebido: à medida que o elétron vai sendo "despido", sua carga elétrica aumenta. Ou seja, a carga elétrica do "elétron nu" é maior do que a do elétron "vestido" (o velho conhecido elétron), o que explica porque a lei de Coulomb não vale para dois elétrons a uma distância inferior a $10^{-11} \mathrm{~cm}$. Quer dizer, em distâncias dessa ordem a força entre dois elétrons é um pouco maior do que aquela que se esperaria a partir da lei de Coulomb (ibid).

Interessante como as coisas mudam no domínio do muito pequeno: as partículas virtuais violam a conservação da energia, mas por muito pouco tempo (se não há um aporte de energia para que uma partícula virtual vire partícula real ela logo desaparece); a lei de Coulomb não dá o resultado esperado porque nesse domínio o elétron pode "ficar nu" e sua carga aumenta porque diminui o efeito da polarização.

Assim como na eletrodinâmica quântica os elétrons estão envolvidos por uma nuvem de pósitrons virtuais, 
na cromodinâmica quântica os quarks estão envoltos em uma nuvem de glúons (o vácuo também está cheio de glúons, partículas igualmente virtuais). Pode-se, então, falar também de quarks "nus" e quarks "vestidos" ou, de um modo geral, em "partículas nuas" e "vestidas".

\section{O campo e o bóson de Higgs}

Teoricamente, o vácuo é preenchido não só pelas partículas virtuais (fantasmas?) e pelos quatro campos fundamentais, mas também por um outro campo fundamental, chamado campo de Higgs e, consequentemente, por uma partícula mediadora que seria o bóson ${ }^{12} d e$ Higgs [7].

Bósons de Higgs são partículas previstas teoricamente, em 1964, pelo físico escocês Peter Higgs e usadas, posteriormente, por Steven Weinberg (1967) e Abdus Salam (1968) para explicar porque outras partículas, os bósons W e Z, têm massa. Havia na teoria eletrofraca, formulada em 1962 por Sheldon Glashow, um paradoxo envolvendo as partículas $W$ e Z. Por um lado, a debilidade das interações fracas requereria que tais partículas tivessem massas relativamente elevadas. Por outro, a simetria da teoria que dava conta dessas interações exigia que suas massas fossem nulas. Tal contradição desapareceria se as massas dos bósons $\mathrm{W}$ e $\mathrm{Z}$ fossem aparentes. Quer dizer, se suas massas fossem "dadas" por outras partículas: os bósons de Higgs. De acordo com o chamado mecanismo de Higgs ${ }^{13}$, as partículas $\mathrm{W}$ e $\mathrm{Z}$ se chocariam incessantemente com outras partículas presentes em todo o espaço, as partículas de Higgs, que explicariam suas massas. Ou seja, a massa das partículas $\mathrm{W}$ e $\mathrm{Z}$ seria dada pela massa das partículas com as quais estariam permanentemente chocando-se. Existiria um campo de Higgs, fundamentalmente diferente dos demais campos pois, segundo a teoria, o estado de energia mínima desse campo ocorreria não quando se anulasse (como é o caso, por exemplo, do campo eletromagnético) mas em um determinado valor específico distinto de zero [1]. Consequentemente, um campo de Higgs não-nulo permeia o universo, e as partículas estão sempre interagindo com ele, deslocando-se através dele como pessoas vadeando na água. Essa interação lhes dá sua massa, sua inércia (ibid., p. 62).

Hoje, o mecanismo de Higgs é considerado como a origem da massa de todas as partículas elementares, mas o paradoxo teórico envolvendo as partículas $\mathrm{W}$ e $\mathrm{Z}$ foi identificado antes que as próprias partículas tivessem sido detectadas. Então, uma vez detectadas as partículas (massivas) W e Z, o problema passou a ser a detecção do bóson de Higgs, o que até agora, passados mais de quarenta anos, ainda não aconteceu, mas que se espera que aconteça antes de 2010.

Isso porque as máquinas, ou seja, os aceleradores/colisores/detectores de partículas até hoje construídos não foram capazes de alcançar uma energia suficiente para criar/detectar bósons de Higgs. Contudo, espera-se que uma máquina chamada LHC (Large Hadron Collider) em construção no CERN (Laboratório Europeu para Física de Partículas), cujo funcionamento está previsto para 2009,14 seja capaz de "descobrir" bósons de Higgs (ou o bóson de Higgs, pois há uma teoria que prevê a existência de um único bóson de Higgs). Ou, então, uma outra máquina, chamada Tevatron, existente no Fermilab nos Estados Unidos poderá também, por suas peculiaridades, permitir a detecção do Higgs.

Aparentemente, ninguém duvida da existência do bóson de Higgs. Parece ser uma questão de tempo e lugar. Quando? Onde? Ah!, e quem? Ganhará o Nobel quem descobrir o bóson de Higgs? Ou deverá ir para Peter Higgs que o previu há quarenta anos atrás?

E se não for detectado? Será necessário modificar o modelo padrão? Fazer nova(s) hipótese(s) auxiliar (es)?

\section{O que é massa afinal?}

Paradoxalmente, a massa, uma propriedade tão familiar da matéria, é um dos assuntos mais pesquisados na física de partículas. Os físicos querem explicar essa propriedade, querem explicar por que as partículas têm massa. Isso, como visto na seção anterior, tem a ver com o bóson de Higgs e melhorará e estenderá o Modelo Padrão. Nesta seção, esse assunto será explorado um pouco mais. Mas antes, vejamos o que hoje se considera concepções alternativas (misconceptions) sobre massa, na visão de Okun [8, p. 12-13].

"Massa de repouso" e "massa relativística" é uma terminologia antiga, do início do século XX, para manter a relação newtoniana entre momentum, massa e velocidade $(\mathbf{p}=m \mathbf{v})$. No entanto, a relação correta é a expressão relativística $\mathbf{p}=m \mathbf{v} / \sqrt{1-v^{2} / c^{2}}$ de modo que levando em conta que $\mathbf{F}=d \mathbf{p} / d t$, a expressão $\mathbf{F}=m \mathbf{a}$ é válida apenas no limite não-relativista onde $v / c<<1$.

Na mecânica relativista, a "massa de repouso" não é nem a massa inercial (i.e., o coeficiente de proporcionalidade entre força e aceleração) nem a massa gravitacional (i.e., o coeficiente de proporcionalidade entre

\footnotetext{
${ }^{12}$ Bósons são partículas com spin (momentum angular intrínseco) inteiro que não obedecem o Princípio da Exclusão de Pauli (duas partículas com o mesmo spin não podem ocupar o mesmo estado ao mesmo tempo).

${ }^{13}$ Os físicos Robert Brout e François Englert também são responsáveis pelo desenvolvimento desse aparato teórico, mas na literatura ele é usualmente referido apenas como mecanismo de Higgs.

${ }^{14} \mathrm{~A}$ expectativa era que essa máquina, cujo custo é de cerca de 8 bilhões de dólares, começasse a funcionar em 2008 e, de fato, os primeiros testes foram feitos em setembro de 2008, mas precisou ser desligada por problemas técnicos (aquecimento de supercondutores). Os reparos levaram um certo tempo e, então, novos testes terão que esperar o término do inverno europeu, por questões de economia de energia elétrica. Espera-se, assim, que 2009 seja o ano do LHC (e do bóson de Higgs).
} 
o campo gravitacional e a força gravitacional atuando em um corpo).

A atração gravitacional não é determinada pela "massa de repouso", pois um fóton é defletido pelo campo gravitacional apesar de ter massa nula. Como a atração gravitacional sobre um fóton aumenta com a energia do fóton somos tentados a aceitar que pelo menos nesse caso tem sentido falar em massa relativística, ou massa de movimento, mas isso não é correto. Uma teoria consistente do movimento de um fóton (ou qualquer outro objeto movendo-se com velocidade comparável à da luz) em um campo gravitacional mostrará que a energia de um corpo não é equivalente a sua massa gravitacional.

Outro exemplo dessa desafortunada terminologia é a falsa afirmação de que na física de altas energias e na física nuclear é possível transformar energia em matéria e matéria em energia. A energia se conserva. A energia não se transforma em coisa alguma, são apenas distintas partículas que se transformam umas em outras. $\mathrm{Ou}$ seja, a energia se conserva mas os portadores de energia, e a forma em que ela aparece, de fato, mudam.

Concluindo, os termos "massa de repouso" e "massa relativística" (ou "massa de movimento") não devem ser mais usados e massa deve significar sempre a massa relativisticamente invariante da mecânica de Einstein (op. cit.)

Massa é, então, simplesmente massa, uma propriedade intrínseca de certas partículas elementares. Os quarks, por exemplo, têm massa. Os fótons e outras partículas virtuais não têm massa. Mas a gravidade atua também em fótons, ou seja, atua sobre energia, não só sobre massa.

Energia e massa estão relacionadas pela equação de Einstein $E=m c^{2}$, mas isso não significa que a massa seja dependente da velocidade. Este assunto está muito bem discutido no artigo $E=m c^{2}$ : origem e significados [9].

Mas por que têm massa as partículas que têm massa? Como se explica a massa? Este é um problema que o Modelo Padrão espera resolver com o campo e o bóson de Higgs.

A aquisição de massa por uma partícula poderia ser explicada da seguinte maneira: o campo de Higgs estaria permeando todo o espaço; a partícula mediadora desse campo seria o bóson de Higgs. Uma partícula real nesse espaço interagiria com o campo e ficaria polarizada com bósons de Higgs que lhe dariam então massa. Haveria uma nuvem de bósons de Higgs associada à partícula dando-lhe massa. Metaforicamente seria análogo ao que aconteceria com uma pessoa muito importante, ou muito conhecida, que chegasse a uma festa, ou seja, a um "campo de pessoas", e imediatamente muitas outras pessoas viessem cumprimentá-la e permanecessem ao redor dela onde ela fosse. Ou o que aconteceria com um vendedor de sorvete que passasse por um "campo de crianças" [1].

Note-se que, a rigor, o que daria massa às partículas seria o campo de Higgs, caso contrário seria necessário outro mecanismo para explicar a massa do bóson de Higgs. Um único campo de Higgs seria suficiente para explicar a massa das partículas, mas poderia haver outros tipos de campos de Higgs. Aliás, o Modelo Padrão Supersimétrico (uma extensão do Modelo Padrão) prevê a existência de cinco bósons de Higgs (op. cit., p. 34). Até agora nenhum foi detectado, mas no LEP (Large Electron-Positron Collider) já foram obtidas evidências experimentais indiretas de que eles existem. Sua detecção, como já foi dito, parece ser uma questão de tempo. E de máquina!

\section{A antimatéria}

A antipartícula de uma dada partícula tem a mesma massa e spin dessa partícula, porém carga elétrica oposta, assim como opostos o número bariônico, $\frac{15}{\mathrm{O}}$ número leptônico, e assim por diante. Para cada partícula existe uma antipartícula. Assim, a antimatéria é constituída de antiprótons, antinêutrons, antielétrons (chamados pósitrons), antiléptons, antiquarks. Partículas neutras como os fótons são iguais as suas antipartículas [5]. (Grávitons também seriam iguais as suas antipartículas.)

No início dos anos trinta, parecia que a matéria era constituída de prótons, nêutrons e elétrons, e a interação eletromagnética explicava porque os elétrons (negativos) ficavam ligados aos núcleos (positivos) nos átomos. Mas isso não durou muito porque para explicar a estabilidade do núcleo foi preciso postular uma nova interação fundamental, a interação forte, e para uma descrição do elétron que satisfizesse à teoria quântica e à teoria da relatividade foi necessário prever a existência de antipartículas. Isso foi feito por Paul Dirac e, logo depois, em 1933, Carl Anderson detectou em raios cósmicos a antipartícula do elétron (antielétron ou pósitron)

Antiprótons e antinêutrons foram descobertos nos anos cinquenta. Desde 1955, os físicos de partículas vêm criando feixes de antiprótons e desde 1995 conseguem criar antiátomos (pares antipróton-antielétron, formando antiátomos de hidrogênio) [10].

Mas por que "criar" antipartículas e antiátomos? Não existem na natureza?

Existem, mas há no universo uma assimetria matéria/antimatéria: há mais matéria do que antimatéria. Há no universo uma imensa quantidade de matéria, mas são raras as antipartículas que ocorrem naturalmente. Esta situação pode ser embaraçosa para a física de partículas, mas é afortunada para o mundo em que vivemos: matéria e antimatéria quando em con-

\footnotetext{
${ }^{15}$ Número bariônico é o número total de bárions presentes em um sistema menos o número total de antibárions. Analogamente, número leptônico é o número total de léptons presentes em um sistema menos o número total de antiléptons.
} 
tato se aniquilam mutuamente e convertem sua massa total em uma quantidade equivalente de energia, ou seja, próton e antipróton se aniquilam produzindo um raio gama com a energia equivalente à soma de suas massas; elétron e antielétron se aniquilam, e assim por diante, matéria e antimatéria se aniquilando mutuamente. Isso significa que um universo composto da mesma quantidade de matéria e antimatéria seria hostil e instável, não o tipo de lugar onde grandes quantidades de matéria do tamanho de planetas poderiam existir em relativa paz e estabilidade durante bilhões de anos [11].

O processo de produção de antipartículas é o contrário da aniquilação. Parte da energia produzida em colisões provocadas nos aceleradores de partículas é convertida, por exemplo, em pares de prótons e antiprótons.

\section{A simetria CPT}

O interesse por pesquisar antipartículas é, primariamente, teórico: o chamado teorema da simetria CPT que relaciona as propriedades das partículas e suas antipartículas; de acordo com a teoria, ambas devem seguir as mesmas leis físicas.

CPT significa "reversão da Carga", "inversão da Paridade" e "reversão do Tempo". Reversão da carga é a substituição de todas as partículas por antipartículas. Inversão da paridade é a reflexão especular ou inversão do espaço em relação a um ponto e reversão do tempo significa passar o "filme" da realidade de trás para frente [10, p. 58].

Dizer que a natureza é invariante frente à simetria $\mathrm{P}$ significa que qualquer processo físico observado em um espelho segue as mesmas leis do processo não refletido. Embora pareça óbvia, tal simetria é quebrada na interação fraca envolvida em certos decaimentos radioativos. De um modo geral, em muitas situações em que a simetria P é quebrada a simetria CP é preservada, mas em raras ocasiões a simetria $\mathrm{CP}$ é também quebrada e essa quebra pode ter a ver com a predominância da matéria sobre a antimatéria no universo (ibid.). A violação da simetria CP permitiria que partículas e antipartículas decaíssem com taxas diferentes.

Outro aspecto intrigante da assimetria matéria/antimatéria é que das quatro forças fundamentais - eletromagnética, gravitacional, forte e fraca - apenas a fraca afetaria diferentemente a matéria e a antimatéria. Ou seja, em qualquer reação causada pelas forças eletromagnética, gravitacional e forte, se novas partículas fossem produzidas elas o seriam em iguais quantidades e tipos de matéria e antimatéria. Estas forças não poderiam então explicar o predomínio da matéria sobre a antimatéria. A força fraca talvez sim, mas isso permanece ainda como um grande desafio para os físicos de partículas [11, p. 16].

Voltando à questão das simetrias, se a simetria $\mathrm{CP}$ também é violada em certos processos, resta a sime- tria CPT. A expectativa dentro do Modelo Padrão das partículas elementares é que qualquer violação da simetria CPT deve ser muito pequena. No Modelo Padrão, a simetria CPT é uma propriedade fundamental do universo. Violações significativas dessa simetria indicariam problemas no Modelo Padrão e sugeririam a necessidade de uma teoria que fosse além dele. Daí o interesse em produzir antipartículas e antiátomos, nos grandes aceleradores nos Estados Unidos e na Europa, a fim de estudar profundamente suas propriedades.

\section{EDQ \& CDQ}

A teoria das interações entre fótons e elétrons é chamada Eletrodinâmica Quântica (EDQ); correspondentemente, a teoria das interações entre glúons e quarks é chamada de Cromodinâmica Quântica (CQD); (quarks têm a propriedade cor; chromos em grego significa cor). Há, no entanto, uma grande diferença entre as duas quando se leva em conta a natureza das partículas fundamentais envolvidas (elétrons e quarks): elétrons podem ser detectados livremente, quarks não. Além disso, três quarks formam hádrons e estes são "brancos", mas três elétrons formariam um estado (não ligado) com carga - $3 e$, pois a carga elétrica se conserva. Isso significa que ao invés de uma carga, como na eletrodinâmica, na cromodinâmica há várias cargas cor (são oito) e que a adição destas cargas não é uma simples soma escalar. Lembremos que cor é uma propriedade da matéria que no caso dos quarks apresenta três variedades (vermelho, verde e azul), porém no caso dos glúons, combinando estas três cores e suas anticores, chega-se a nove glúons, mas um deles é branco, restando, então, oito glúons coloridos. Daí dizer-se que na CQD há oito cargas cor [5, p. 142].

Prosseguindo com a analogia entre essas duas teorias, observa-se que um campo eletrodinâmico cria uma força de atração entre dois objetos carregados com cargas opostas, a qual em termos quânticos é criada através da troca de fótons virtuais entre esses objetos, da mesma forma que um campo cromodinâmico criaria uma força de atração entre quarks através da troca de algumas partículas virtuais análogas aos fótons virtuais. Tais partículas, como foi visto, são chamadas glúons.

Pode-se então "construir" um espaço cromodinâmico no qual as cargas cor fazem o papel da carga elétrica no espaço eletrodinâmico e os glúons o dos fótons virtuais. Contudo, o acoplamento de glúons a quarks é mais complicado do que o acoplamento de fótons a elétrons, pois quando um fóton interage com um elétron este permanece sendo um elétron, porém um glúon interagindo com um quark pode mudar a cor do quark, isto é, transformá-lo em um outro quark. Quer dizer, as cores dos quarks podem mudar quando eles interagem com glúons.

É preciso, no entanto, reiterar que a analogia não é total porque, como foi dito, na eletrodinâmica há uma 
única carga, a elétrica, enquanto que na cromodinâmica há oito cargas cor distintas, ou oito glúons coloridos.

\section{A matéria escura}

Estrelas, planetas, cometas, poeira cósmica e outras formas ordinárias de matéria parecem constituir aproximadamente $5 \%$ da massa do universo. Os outros 95\% seriam de "matéria escura" e "energia escura", 16 se é que isso, que não se sabe o que é, de fato existe. Astrônomos há décadas buscam registros da existência da matéria escura e, aparentemente, estão convencidos de que ela existe, mas a evidência obtida não é, ainda, de todo convincente. Há alguns anos os físicos de partículas passaram a participar do esforço dos astrônomos tentando detectar, experimentalmente, partículas de matéria escura. É uma tarefa, em princípio, muito difícil, que conduz a um dilema análogo ao do bóson de Higgs: ou se as detecta e verifica-se que a matéria escura existe ou as teorias que subjazem à física moderna terão que ser modificadas [13].

A hipótese da matéria escura está ligada à questão de se o universo continuará em expansão ou se esta diminuirá e será revertida levando eventualmente a um período de contração. Essa questão está relacionada a outra: quanta massa existe no universo? Dependendo da quantidade, a expansão poderá ser revertida e, inclusive, ocorrer um "Big Crunch", 17 ou continuará para sempre. A primeira possibilidade é conhecida como universo fechado, a segunda como universo aberto. Entre elas, há a do universo plano, ou seja, existiria uma "massa crítica" do universo, suficiente para reduzir a expansão mas não suficiente para revertê-la.

Estimando a massa do universo a partir da matéria visível, o resultado seria, como foi dito antes, muito pequeno e teríamos o chamado universo aberto. No entanto, há evidências experimentais, ainda que não totalmente convincentes, sobre a existência de uma matéria escura que permearia o universo. Combinando a massa da matéria observável com a massa estimada da matéria escura, o resultado é bastante próximo da "massa crítica", deixando ainda aberta a questão de se o universo continuará em expansão ou acabará se contraindo [4, p. 394].

Supondo, então, que a matéria escura existe, a pergunta que surge de imediato é "de que tipo de partícula seria ela constituída?".
Neutrinos eram fortes candidatos porque deve haver no universo uma enorme quantidade dessas partículas elusivas resultantes do Big Bang, os chamados neutrinos primordiais, produzidos nos primeiros segundos de Big Bang. Na verdade, seriam candidatos ideais se não fosse o problema de sua massa ser muito pequena. Mesmo existindo em abundância contribuiriam com uma pequena fração da matéria escura [13, p. 59].

\section{O vento escuro}

Na verdade, nenhuma das partículas do Modelo Padrão responde à pergunta da constituição da matéria escura.

Consequentemente, tentativas de extensões do Modelo Padrão estão sendo feitas. Uma delas é a da $S u$ persimetria, a qual pressupõe a existência de toda uma nova família de partículas: cada partícula elementar do Modelo Padrão teria uma "superparceira" mais pesada. Sendo mais pesadas, essas partículas seriam, portanto, mais lentas do que as partículas conhecidas, constituindo, então, o que se poderia chamar de matéria escura "fria" 18 Destas, uma possibilidade atraente para físicos e astrônomos é o neutralino, uma amálgama das superparceiras do fóton, do bóson Z (que transmite a força fraca) e talvez de partículas de outros tipos (ibid.).

O neutralino seria a mais leve das superpartículas; como sugere o nome, teria carga elétrica zero (portanto, não afetada por forças eletromagnéticas) e seria estável. Sua estabilidade e neutralidade associadas a uma determinada massa, satisfariam todos os requisitos da matéria escura fria.

A teoria do Big Bang permite uma estimativa do número de neutralinos que teriam sido criados no plasma quente inicial do universo. Esse plasma era uma sopa caótica de todos os tipos de partículas, nenhuma das quais sobreviveu por muito tempo: imediatamente colidiam com outras partículas aniquilando-se mutuamente e produzindo novas partículas que também colidiam com outras e assim por diante em um processo cíclico de criação e destruição. Mas à medida que o universo esfriava e se tornava menos denso as colisões eram menos violentas e menos frequentes, permitindo que as partículas condensassem progressivamente. $\mathrm{O}$ neutralino seria uma partícula menos propensa a colisões de modo que teria sido uma das primeiras a condensar 19 Então, nesse período teria sido produzida uma imensa quantidade de neutralinos cuja massa to-

\footnotetext{
${ }^{16}$ Apesar do nome similar, matéria e energia escura são substâncias distintas: matéria escura é uma forma exótica de matéria que não emite, não absorve, nem espalha luz; a única interação à qual ela reage é a gravitação. Energia escura é um novo ingrediente que entrou em cena recentemente para explicar o universo porque as formas conhecidas de matéria e a matéria escura dão conta de apenas aproximadamente $30 \%$ dele. Os outros $70 \%$ seriam explicados pela energia escura que se distingue da matéria escura pelo fato de ser gravitacionalmente repulsiva levando o universo a uma expansão acelerada. Ou seja, o universo estaria dominado por uma energia escura que permeia todo o cosmos e que ainda não sabemos o que é. (12, pp.306-311).

${ }^{17}$ Crunch significa esmagamento ruidoso.

${ }^{18}$ A matéria escura "quente" seria aquela dos primórdios do universo, constituída de partículas que se moviam com velocidades comparáveis à luz.

${ }^{19}$ Nessa sopa primordial, quarks e glúons também teriam reduzido muito suas velocidades de modo que após alguns microssegundos acabaram unidos por forças muito fortes e permanentemente confinados dentro de prótons, nêutrons e outras partículas chamadas hádrons [14, p. 40].
} 
tal corresponde bastante bem com a massa estimada de matéria escura existente no universo (op. cit., p. 60).

Teoricamente, então, a existência do neutralino resolve o problema da matéria escura. Consequentemente é preciso detectá-lo. Mas para isso é necessário saber como interage com a matéria normal. Se a interação for apenas a gravitacional, não há esperanças de detectá-lo pois a força gravitacional é a mais fraca de todas no domínio das partículas elementares. No entanto, a teoria da supersimetria prevê que o neutralino interagiria com a matéria através da força nuclear fraca. Se assim for, há possibilidades de detectá-lo pois embora a força seja fraca o número previsto de partículas é imenso. Como foi dito no início desta seção, a matéria escura é dominante no universo. Sendo escura não emite radiação, não perde energia e não se aglomera para formar estrelas e planetas. Quer dizer, a matéria escura permeia o espaço interestelar como se fosse um gás. Seria um gás estagnado, ou seja, as partículas que o constituem se moveriam, mas aleatoriamente, sem movimento organizado. No entanto, como nosso sistema solar está orbitando em torno do centro de nossa galáxia a $220 \mathrm{~km}$ por segundo estaríamos sofrendo o impacto de um "vento escuro" que segundo estimativas dos cientistas seria da ordem de um milhão de partículas escuras por metro quadrado por segundo.

Há pelo menos uma dezena de laboratórios tentando detectar o neutralino desde 1997. Além da dificuldade inerente ao fato de que a interação da matéria escura com a matéria comum é fraca, há o problema de que os detectores, sendo construídos de metal, contêm traços radioativos de elementos como urânio e tório que decaem produzindo partículas que são confundidas com partículas escuras. A dificuldade não é tanto de sensibilidade, mas de impureza intrínseca aos detectores (op. cit., p. 61).

Até meados dos anos setenta a física de partículas e a cosmologia eram áreas de pesquisa completamente separadas, porém, nessa época, talvez em função de grandes cortes de verbas, pesquisadores em física de partículas se deram conta que estudos sobre os primórdios do universo ofereciam uma possibilidade única de investigar fenômenos de alta energia que não podiam ser recriados em laboratório [15]. Surgiu assim a cosmologia de partículas, uma área híbrida e altamente promissora em física.

\section{Neutrinos oscilantes}

O Modelo Padrão inclui três tipos distintos de neutrinos: neutrino do elétron, neutrino do múon e neutrino do tau. Haveria, então, três "sabores" distintos de neutrinos. De acordo com a teoria proposta pelo físico inglês Arthur Eddington, em 1920, a energia do Sol seria proveniente de reações de fusão nuclear que ocorreriam no seu interior. Mais tarde, com a hipótese de Pauli (1930) sobre a existência do neutrino e ainda de- pois com o Modelo Padrão, chegou-se, teoricamente, à conclusão de que tais reações produziriam neutrinos do elétron em abundância. Contudo, desde os anos 60 até 2002 os experimentos para detectar esses neutrinos solares sempre davam resultados significativamente inferiores aos previstos pela teoria. Essa incômoda diferença que ficou conhecida como o problema dos neutrinos solares [16] era também um problema do Modelo Padrão. Quer dizer, uma previsão do Modelo Padrão não era confirmada pelos resultados experimentais. Em alguns casos, o número de neutrinos detectados era apenas um terço do previsto.

Somente em 2002, físicos do Observatório de Neutrinos SudBury, em Ontário, resolveram este problema confirmando experimentalmente a hipótese dos físicos Gribove e Pontecorvo, feita em 1969, supondo que os neutrinos produzidos no interior do Sol mudam de sabor antes de chegar à Terra. Ou seja, o número de neutrinos do elétron produzidos nas reações de fusão nuclear, previsto teoricamente, estava bem, mas o número detectado na Terra seria menor porque os neutrinos do elétron se convertiam em outros neutrinos não detectáveis pelos experimentos montados até então para detectar neutrinos solares. Essa hipótese dos neutrinos oscilantes depois de confirmada experimentalmente resolveu o problema dos neutrinos solares, confirmou a teoria de Eddington e eliminou essa anomalia existente no Modelo Padrão. Por outro lado, levou a uma modificação no Modelo Padrão pois, segundo a teoria, os neutrinos seriam partículas sem massa, mas os novos resultados implicavam que eles teriam massa, ainda que muito pequena (op. cit., p. 24).

A hipótese da oscilação dos neutrinos requer que os três sabores de neutrino (do elétron, do muón e do tau) sejam constituídos de misturas de estados de neutrinos (identificados como 1, 2 e 3) com diferentes massas. Um neutrino do elétron poderia ser então uma mistura de estados 1 e 2 enquanto que um neutrino do muón seria uma mistura diferente desses mesmos estados. De acordo com essa hipótese, enquanto viajam (8 min!) até a Terra, esses neutrinos, constituídos de distintas misturas, oscilam entre um e outro sabor. Há vários modelos para a oscilação dos neutrinos, supondo que a oscilação ocorre ainda no próprio Sol, ou que ocorre no espaço vazio ou, também, que acontece no interior da Terra (eles praticamente não interagem com a matéria), tudo dependendo da mistura e da diferença de massas. Resultados experimentais recentes, no observatório de neutrinos antes referido, indicam que do total de aproximadamente 5 milhões de neutrinos solares que chegam à Terra por $\mathrm{cm}^{2}$ por segundo cerca de dois terços são neutrinos do tau ou neutrinos do muón. Como as reações de fusão nuclear no interior do Sol só produzem neutrinos do elétron, tais resultados confirmam a hipótese dos neutrinos oscilantes.

Oscilantes ou não, os neutrinos constituem um dos mais fascinantes tópicos da física de partículas. São di- 
tos elusivos, ou seja, ariscos, evasivos, fugidios, de difícil compreensão. Ao que parece, quanto mais os físicos de partículas souberem sobre os neutrinos mais saberemos sobre a natureza da matéria, sobre a formação de galáxias, sobre a assimetria matéria - antimatéria.

\section{Conclusão}

Como foi dito no início, o Modelo Padrão é uma excelente teoria, a melhor que já tivemos sobre a natureza da matéria. É uma teoria que identifica as partículas constituintes da matéria e descreve como elas interagem. Além disso, o faz apresentando várias simetrias e sempre buscando outras.

Mas não é uma teoria acabada, nem definitiva. Ao contrário é, como todas as demais teorias científicas, uma verdade provisória, no sentido de que, seguramente, será modificada, completada, extrapolada, a fim de explicar melhor o que se propõe e, em algum momento, dará lugar a outras teorias que, de alguma forma, nela estarão apoiadas.

Dentre os problemas que enfrenta o Modelo Padrão pode-se destacar os seguintes [1, pp. 61-62].

- A assimetria matéria - antimatéria: se o universo começou no Big Bang como uma imensa explosão de energia, ele deveria ter evolvido em partes iguais de matéria e antimatéria (simetria $\mathrm{CP}$ ). Ao invés disso, estrelas e nebulosas são feitas de prótons, elétrons e nêutrons e não de suas antipartículas. Essa assimetria não é explicada pelo Modelo Padrão. Há no universo muito mais matéria do que antimatéria.

- A matéria escura e a energia escura: a maior parte do universo é constituída da chamada matéria escura e da energia escura, que não são formadas pelas partículas do Modelo Padrão.

- O campo de Higgs: a interação com o campo de Higgs, mediada pelo bóson de Higgs, daria massa às partículas. Espera-se que o bóson de Higgs seja detectado nos próximos anos, mas mesmo que isso venha, de fato, a ocorrer, o Modelo Padrão tem dificuldades para explicar formas particulares dessa interação. Uma delas é que pelos cálculos da teoria atual a massa do bóson de Higgs seria muito grande e, consequentemente, as partículas do Modelo Padrão teriam massas também muito grandes.

- A gravidade: o gráviton nunca foi detectado e o Modelo Padrão não consegue incluir a interação gravitacional porque ela não tem a mesma estrutura das outras três interações.

Tais problemas poderão ser resolvidos. A detecção do bóson de Higgs será mais um êxito espetacular do Modelo Padrão. A hipótese dos neutrinos oscilantes resolveu o problema da grande diferença entre o número de neutrinos previstos e o número de neutrinos detectados na Terra. A detecção do neutralino resolveria o problema da matéria escura.
A gravidade poderá continuar sendo a grande "dor de cabeça" do Modelo Padrão [4, p. 99). Mas mesmo que se encontre alguma solução para este problema conceitual da teoria, os físicos acreditam que ela deverá ser suplantada por outra mais completa. Modelos Padrão Supersimétricos $[1,17]$ são sérios candidatos.

Mas se o Modelo Padrão, apesar das anomalias, é uma teoria tão bem sucedida por que os físicos buscam suplantá-la? Não seria o caso de conviver com as dificuldades?

A resposta é sim e não. Por um lado, é normal que as teorias científicas tenham problemas que não conseguem resolver, desde que resolvam muitos outros. Por outro, o progresso do conhecimento científico depende de novas teorias, com maior poder explicativo.

Para Bachelard [18], por exemplo, o conhecimento científico é um permanente questionar, um permanente não ao conhecimento anterior, mas não no sentido de negação, e sim no de conciliação: cada nova teoria diz não à teoria antiga e assim avança o pensamento científico. A filosofia do não de Bachelard surge não como uma atitude de recusa, mas sim como de reconciliação. A nova teoria diz não à anterior, mas surge a partir dela.

Essa filosofia do não é também uma filosofia $d a d e-$ silusão. Ou seja, o conhecimento científico é sempre a reforma de uma ilusão, é fruto da desilusão com o que julgávamos saber [19].

A superação do Modelo Padrão, na óptica de Bachelard, será uma consequência natural da desilusão que teremos com ele, da necessidade de dizer não a ele se quisermos aprender mais sobre partículas elementares e suas interações, sobre a matéria escura, a antimatéria, o campo de Higgs e outros tópicos abordados neste artigo.

As teorias científicas estão sempre em construção. Neste artigo procurou-se ilustrar, com o Modelo Padrão, esta faceta fascinante da ciência.

\section{Agradecimento}

O autor agradece aos Professores Eliane Veit e Paulo Mors, do Instituto de Física da UFRGS, pela revisão crítica de versões iniciais deste trabalho; agradece também ao revisor da RBEF pelas valiosas sugestões recebidas.

\section{Referências}

[1] G. Kane, Scientific American 288(6), 56 (2003).

[2] N.N. Scoccola, Ciência Hoje 210, 36 (2004).

[3] H.C. Ohanian, Physics (New York, W.W. Norton \& Company, 1985), p. G-9.

[4] L. Lederman and D. Teresi, The God Particle. If the Universe is the Answer, What is the Question? (Dell Publishing, Nova York, 1993). 
[5] H. Fritzsch, Quarks: The Stuff of Matter (Basic Books Inc., Nova Iork, 1983).

[6] L.C. Menezes, A Matéria: Uma Aventura do Espírito (Livraria Editora da Física, São Paulo, 2005).

[7] P.Y. Colas y B. Tuchming, Mundo Científico/La Récherche 247, 46 (2004).

[8] L.B. Okun, $\alpha, \beta, \gamma \ldots$ Z. A Primer in Particle Physics (Harwood Academic Publishers, Newark, 1987).

[9] N.A. Lemos, Revista Brasileira de Ensino de Física 23, 3 (2001).

[10] G.P. Collins, Scientific American 290(6), 57 (2005).

[11] B.A. Schumm, Deep Down Things. The Breathtaking Beauty of Particle Physics (The Johns Hopkins University Press, Baltimore, 2004).
[12] M.C.D. Abdalla, O Discreto Charme das Partículas Elementares. (Editora da UNESP, São Paulo, 2006).

[13] D. Cline, Scientific American 288(3), 28 (2003).

[14] M. Riordan e W.A. Zajc, Scientific American Brasil 4(49), 40 (2006).

[15] D. Kaiser, Scientific American 292(6), 40-(2007).

[16] A.B. McDonald, J.R. Klein and D.L. Wark, Scientific American 288(4), 22 (2003).

[17] J.A. Helayël-Neto, Física na Escola 6(1), 45 (2005).

[18] G. Bachelard, A Filosofia do Não (Editorial Presença, Lisboa, 1991).

[19] A.R.C. Lopes, Caderno Catarinense de Ensino de Física 13, 248 (1996). 